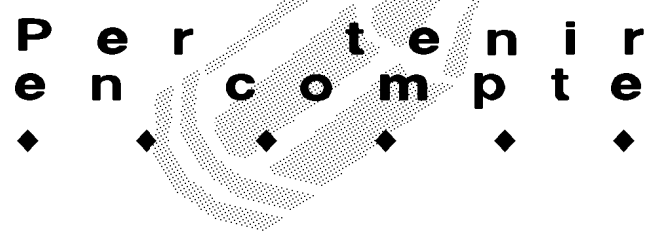

\title{
L'AEMCAT: ASSOCIACIÓ D'ENSENYANTS DE MÚSICA DE CATALUNYA
}

\author{
Associació d'Ensenyants de Música de Catalunya. Figueres
}

L'Associació d'Ensenyants de Música de Catalunya (AEMCAT) és una entitat que va néixer amb l'objectiu de ser un punt d'unió, de comunicació i d'intercanvi entre totes i tots els que treballem en el món de l'ensenyament musical, a escoles $i$ instituts de Catalunya. El gener del 2006 comptava ja amb més de 100 sòcies $i$ socis d'arreu de Catalunya.

L'AEMCAT, com moltes de les associacions sense ànim de lucre, es crea quan un col-lectiu troba a faltar un marc, un espai, un lligam. Bé, el nostre col-lectiu de mestres de música ja té el seu espai dins les activitats de formació que ens ofereix el Departament d'Educació a nivell comarcal dins el Pla de Formació de Zona, però les petites "enganxades" amb l'administració (els greuges entre especialitats, ja sigui d'hores lectives o de qualsevol altra qüestió) no les pot assumir el seminari o el grup de treball. No té capacitat ni mitjans per fer que la seva veu se senti.

Va ser, doncs, des de dos seminaris on es van començar les converses per crear una entitat que vetllés per tots. L'entitat, de bon començament, no pretenia anar més enllà de les comarques de Girona: Empordà, Gironès, Garrotxa... però -i aprofitant que a Girona s'estaven celebrant unes jornades de pedagogia musical- es van repartir 300 enquestes on es preguntava als docents si també en veien la necessitat. La resposta ens arribava de Menorca, de Granollers, de Tarragona, de la Cerdanya... i tots i totes valoraven molt positivament el naixement d'aquesta associació a nivell català.

Així doncs, aquest "motor" inquiet va repartir als seminaris de tot Catalunya la covocatòria per a una reunió fundacional, que es va celebrar a la Universitat de Girona el dia 18 de maig de 2002. Així va ser com va néixer l'AEMCAT.

\section{Els objectius}

Els objectius els teníem clars, érem la veu de tots $\mathrm{i}$ cadascun dels mestres de música, i havíem de lluitar per fer-la sentir. Aquests són:

- Donar suport i assistència als membres de l'associació en l'exercici de la seva professió.

- Afavorir l'ensenyament, la recerca i la difusió de l'educació musical a Catalunya.
- Contribuir a la millora de les condicions pedagògiques de l'ensenyament de la música.

- Fomentar totes les activitats que afavoreixin la formació del professorat.

- Impulsar i facilitar entre els ensenyants intercanvis de tota mena (llibres, revistes, material pedagògic, etc.).

- Promoure reunions, cursets, col-loquis, congressos i, en general, totes les activitats que puguin ser d'interès.

- Divulgar documentació pedagògica, articles d'investigació i materials que es relacionin amb l'ensenyament de la música.

- Potenciar la col-laboració entre grups i associacions amb objectius similars de dins i de fora de Catalunya.

- Fer d'interlocutors davant de l'Administració per negociar qualsevol tema relacionat amb les millores de treball que hagi decidit l'assemblea.

- Qualsevol altre objectiu que es decideixi en una assemblea legal de l'associació.

- Prestar servei sense ànim de lucre als socis.

\section{Serveis als socis}

La llista de distribució de correu funciona d'allò més bé i ajuda a solucionar ràpidament petits problemes 0 dubtes, amb la colllaboració desinteressada dels membres de l'associació. És l'eina més utilitzada: és el suport per al dia a dia de l'aula, ja que sempre sorgeixen mancances, o fa falta una partitura o no sabem l'autor d'una cançó... Potser el que necessitem és un cop de mà per passar una melodia a midi, o volem fer un karaoke amb els nens/es de l'escola i no sabem ni per on començar. L'AEMCAT som tots, i per tant sempre hi ha algú que ens pot ajudar. La llista de correu serveix per a això, per al suport a la docència.

L'any 2005 la llista va recollir més de 500 missatges. Demandes com cançons de benvinguda originals, cançons relacionades amb la pau, partitures de moltes cançons, consells tècnics per a aspectes musicals...

Hi ha d'altres qüestions que també sorgeixen a la llista de correu, però que no tenen una sol.lució tan fàcil, són els aspectes més legals. La junta de l'AEMCAT ha 


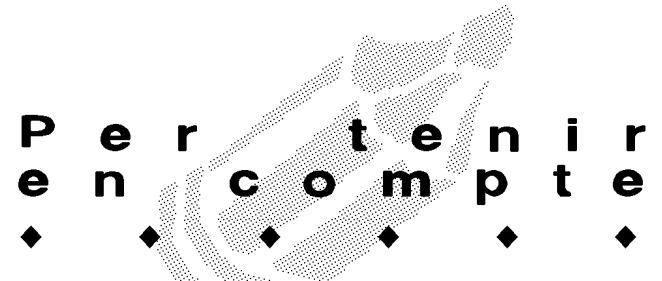

fet molts viatges a via Augusta (seu del Departament d'Educació) per parlar de les lleis que ens regeixen i debatre aspectes que no ens són gens favorables.

Dues vegades en aquests quatre anys hem escampat la nostra veu a tot el territori demanant el suport per superar problemes, i amb les signatures a la mà hem anat a veure els responsables d'Educació (hem tingut el suport de músics reconeguts com Lluís Llach, Albert Guinovart, Manel Camp, Pemi Rovirosa...).

Quant a la divulgació de materials, articles... naixent al s. XXI l'associació havia de comptar amb un espai web. Una finestra que ens obrís al món. Per a socis i no socis. Hi ha informació que ha de poder arribar a tothom, afiliat o no, vinculat o no al món de la docència. Aquest espai és: http://www.aemcat.org. Allà s'hi troben les activitats, enllaços, informacions i també un espai restringit on els socis poden trobar algun dels materials que al llarg d'aquests anys s'han fet arribar per mitjà de la llista de correu.

\section{Presència de l'AEMCAT}

Responent a altres punts als quals l'associació s'havia compromès a portar a terme, hi ha els de promoure, organitzar i també, per què no?, participar en activitats dins el nostre àmbit. És així que hem estat presents en un munt de trobades, taules rodones, reunions amb altres col-lectius, sindicats, partits polítics... quasi totes a Catalunya, però la veu de l'AEMCAT la fem sentir també a Madrid, ja que formem part de la "Confederación de Asociaciones de Educación Musical" (COAEM) d'àmbit estatal. En aquesta confederació hi ha representades totes les comunitats autònomes i la seva funció és bàsicament la d'intercedir directament amb el Ministeri d'Educació.

Dins el nostre territori, l'AEMCAT està adherida al Consell Català de la Música, entitat amb la qual hi ha una estreta relació.

\section{L'AEMCAT, la LOE i el debat curricular}

La relació amb les entitats que acabem d'esmentar, durant el curs passat es va centrar bàsicament en la demanda conjunta de rectificació de la LOE, on l'educació musical quedava totalment difuminada $i$ amb un futur incert: escrits conjunts de la COAEM dirigits al MEC, la demanda de modificació de l'article 24 de la LOE demanada conjuntament amb els sindicats, la unió d'esforços amb el col-lectiu de l'educació visual i plàstica...

Pel que fa al debat curricular proposat pel Departament d'Educació, la nostra associació va presentar dos documents, on es donava l'opinió i se suggerien uns quants canvis de redacció. Aquestes aportacions es poden llegir al web del Debat de la Generalitat de Catalunya.

Moltes de les activitats queden sense ressò si no s'escriuen, si no se'n fa divulgació. Només per aquest motiu, i per poder-ho llegir amb calma, sense estar davant de l'ordinador, un equip -que esperem que s'ampliï ben aviat- nascut dins la junta de l'associació, tira endavant el butlletí que porta per títol: Notes de L'AEMCAT.

Vegeu-lo -si no us ha arribat al centre on treballeu o on heu fet el pràcticum- a la pàgina web http://www. aemcat.org. El primer número correspon a gener de 2006. Aquest primer exemplar està dedicat a les activitats que s'han dut a terme aquest primer trimestre del curs 2005-06 i a la primera Escola d'estiu de Música.

\section{La formació}

Teníem pendent la formació. I és que la docència demana estar al dia. Potser fa certa mandra, però tots acabem fent cursets i cursos, apuntant-nos a activitats concretes. De totes en traiem molt profit.

Per primera vegada, el Departament hi dóna suport i inclou, dins el seu ventall d'oferta per a l'estiu, una escola d'estiu de la nostra especialitat. Per a nosaltres és tot un repte, sabent que els mestres ja coneixen altres grans vies, grans entitats que any rere any organitzen (estiu i hivern) cursos i classes.

Nosaltres apostem per una escola d'estiu on l'intercanvi sigui real, no només al paper, ja que dins l'horari de cada dia hi haurà ponències i també l'espai per a la conversa; on si es vol, els participants conviurem les vint-i-quatre hores durant quatre dies, i serà aquest l'intercanvi, i és clar, també lleure: l'Escola d'Estiu en off (els concerts de la nit).

Us convidem a tots a venir, a aprendre i a gaudir-ne. El títol és suggerent, La música catalana, sense complexos. Els formadors l'han entès bé $\mathrm{i}$ tenen propostes suggerents i divertides, rigoroses però amenes. Hi hem convidat mestres de mestres, músics reconeguts, també hi vindrà gent que treballa estretament amb grups com ara La Cubana, d'altres que en el món de la pedagogia hi tenen un nom...

Podreu estar informats llegint els nostres butlletins, els rebreu al vostre correu electrònic si en sou socis, o a l'escola, o els podreu descarregar des del web. En els propers números anirem avançant informacions. Per ara, les dates: 3, 4, 5 i 6 de juliol. El lloc: El Complex Educatiu de Tarragona. I una frase: ... Una cita ineludible per a tots $i$ totes els que fem bona música a les escoles $i$ instituts.

Ja ho veieu, l'AEMCAT és una associació dinàmica, jove. Les propostes, les demandes, sorgeixen de dins, dels socis que treballen a escoles $i$ instituts, i les solucions, si es pot, es generen a la mateixa entitat. 